\title{
Comunicação
}

\section{Fertilizantes comerciais e polpa de banana no cultivo in vitro de um híbrido de Phalaenopsis (Orchidaceae)}

\author{
Ronan Carlos Colombo ${ }^{1}$, Vanessa Favetta ${ }^{1}$, Ricardo Tadeu de Faria ${ }^{2}$
}

\section{RESUMO}

A propagação in vitro de orquídeas é bastante utilizada para a produção de mudas. A busca por meios de cultura alternativos para este fim vem sendo amplamente estudada devido à complexidade dos meios comumente utilizados, como o meio MS. Os híbridos de Phalaenopsis encontram-se dentre as orquídeas mais comercializadas no mundo devido à longevidade e à beleza peculiar de suas flores. Nesse trabalho, objetivou-se avaliar o efeito de formulações de fertilizantes comerciais e adição de polpa de banana 'Nanica' em meio de cultura no cultivo in vitro de um híbrido de Phalaenopsis ( $P$. amabilis x P. equestris). Plântulas germinadas in vitro, em meio MS, foram subcultivadas em meios de cultura à base de fertilizantes comerciais e meio MS modificado com metade da concentração dos macronutrientes. Os meios de cultura foram avaliados com e sem a adição de polpa de banana 'Nanica' (100 g L L $\left.{ }^{-1}\right)$ no estádio de maturação quatro. A base dos meios de cultura foi composta por sacarose $\left(30 \mathrm{~g} \mathrm{~L}^{-1}\right)$, carvão ativado $\left(1 \mathrm{~g} \mathrm{~L}^{-1}\right)$ e ágar $(9$ $\left.\mathrm{g} \mathrm{L}^{-1}\right)$. Aos 180 dias foram avaliadas as seguintes variáveis: área foliar, número de folhas e raízes, comprimento de raízes e massas de matérias secas de folhas e raízes. Conclui-se que o tratamento composto por Biofert ${ }^{\circledR}$ acrescido de polpa de banana apresentou os melhores resultados para o desenvolvimento in vitro do híbrido, inclusive apresentando resultados estatisticamente superiores em relação ao meio MS sem banana.

Palavras-chave: micropropagação, meio simplificado.

\section{ABSTRACT}

\section{Commercial fertilizers and banana pulp for in vitro cultivation of a Phalaenopsis hybrid}

The in vitro propagation of orchids is a largely used procedure for the production of seedlings. The search for alternative culture media with this purpose has been widely studied due to the complexity of the commonly used media, e.g. the MS medium. The hybrids of Phalaenopsis are among the most commercialized orchids in the world due to the longevity and distinct beauty of its flowers. The objective of this study was to evaluate the effect of commercial fertilizers' formulations and the addition of 'Nanica' banana pulp in a culture medium for in vitro cultivation of a hybrid of Phalaenopsis. Seedlings germinated in vitro, in MS medium, were subcultivated in culture media with a basis of commercial fertilizers and MS medium modified with half the concentration of macronutrients. The culture media were evaluated with and without the addition of the banana pulp $\left(100 \mathrm{~g} \mathrm{~L}^{-1}\right)$ during the stage of maturation 4 . The basis of these culture media was composed of sucrose $\left(30 \mathrm{~g} \mathrm{~L}^{-1}\right)$, activated charcoal $\left(1 \mathrm{~g} \mathrm{~L}^{-1}\right)$ and agar $\left(9 \mathrm{~g} \mathrm{~L}^{-1}\right)$. After 180 days the following variables were analyzed: leaf area, number of leaves and roots, root length and dry weight of leaves and roots. We were able to conclude that the treatment composed by Biofert@ supplemented with banana pulp presented the best results for the hybrid development in vitro, and actually presented statistically superior results in relation to MS without banana.

Key words: Orchidaceae, micropropagation, simplified medium

\footnotetext{
Recebido para publicação em 23/03/2012 e aprovado em 29/08/2012.

${ }^{1}$ Graduandos em Agronomia. Departamento de Agronomia, Universidade Estadual de Londrina, Rodovia Celso Garcia Cid, PR 445, Km 380, Caixa Postal 6001, 86051-980, Londrina, Paraná, Brasil. ronancolombo@yahoo.com.br (autor correspondente); vanfavetta@hotmail.com

${ }^{2}$ Engenheiro-Agrônomo, Doutor. Departamento de Agronomia, Universidade Estadual de Londrina, Rodovia Celso Garcia Cid, PR 445, Km 380, Caixa Postal 6001, 86051-980, Londrina, Paraná, Brasil. faria@uel.br
} 


\section{INTRODUÇÃO}

O gênero Phalaenopsis compreende 66 espécies de orquídeas epífitas, monopodiais, com folhas suculentas (Tsai et al., 2003). São plantas originárias dos trópicos e subtrópicos do planeta, e na atualidade estão entre as orquídeas mais populares produzidas comercialmente (Lee, 2011). Isso se deve ao fato de seu ciclo de produção ser relativamente curto em estufa, se comparado a outras espécies de orquídeas; à longa durabilidade de suas flores, que pode chegar a até três meses; e à enorme gama de variedades com diferentes colorações, formatos e tamanhos, resultantes do processo de hibridação (Vaz \& Kerbauy, 2005; Lee, 2011). Outro aspecto importante dessa orquídea está no fato desse gênero permitir ao produtor programar a sua produção, pois ela responde bem à indução floral, processo que leva ao florescimento a partir de um estímulo provocado, o que não se aplica com sucesso à maioria dos gêneros de orquídeas com interesse econômico (Lee, 2011).

O cultivo in vitro de orquídeas é amplamente difundido entre os laboratórios de cultura de tecidos. Uma das principais vantagens dessa técnica é a produção de plantas em quantidade, aliada à qualidade das mudas (Faria et al., 2012). O meio de cultura é essencial para os desenvolvimentos vegetativo e radicular, podendo conter diferentes combinações de nutrientes, de acordo com os requerimentos de cada espécie (Faria et al., 2002). Dentre os meios de cultura mais utilizados para a propagação in vitro, destacam-se os meios MS (Murashige \& Skoog, 1962), Knudson C (Knudson, 1946) e Vacin e Went (Vacin \& Went, 1949).

Os componentes do meio de cultura podem ser substituídos, em muitos casos, por frutas, legumes, açúcar de uso doméstico (Campos, 2002) e fertilizantes comerciais. No entanto, os conhecimentos sobre a melhor formulação do meio de cultura para cada espécie ainda são limitados (Araújo et al., 2006). A polpa de banana vem sendo muito utilizada nos meios de cultura devido às suas grandes concentrações de potássio, fósforo e magnésio, e também em algumas vitaminas como: vitamina $\mathrm{A}$, tiamina, riboflavina, niacina e vitamina C (Arditti \& Ernest, 1992). Fertilizantes comerciais também têm sido acrescentados aos meios de cultura como fonte de macro e micronutrientes em substituição aos sais normalmente empregados.

Este trabalho objetivou avaliar fertilizantes comerciais em substituição aos sais do meio MS e adição de polpa de banana sobre o desenvolvimento in vitro de plântulas de um híbrido de Phalaenopsis (P. amabilis $\mathrm{x} P$. equestris).

\section{MATERIAL E MÉTODOS}

A partir do cruzamento entre Phalaenopsis amabilis (L.) Blume e P. equestris (Schauer) Rchb. f., obteve-se uma cápsula com sementes viáveis, as quais foram germi- nadas em in vitro, em meio de cultura MS com metade da concentração de macronutrientes. Plântulas com 90 dias de idade e área foliar aproximada de $110 \mathrm{~mm}^{2}$, provenientes de semeadura in vitro em meio de cultura MS com metade da concentração de macronutrientes, foram subcultivadas em frascos de vidro com capacidade de $350 \mathrm{~mL}$, contendo $50 \mathrm{~mL}$ dos seguintes meios: MS modificado, com metade da concentração dos macronutrientes (T1); MS modificado, com metade da concentração dos macronutrientes + banana (T2); Brennfeed 114®, NPK (0505-06) (T3); Brennfeed 114®, NPK (05-05-06) + banana (T4); Dyna-Gro®, NPK (09-03-06) (T5); Dyna-Gro®, NPK (09-03-06) + banana (T6); Biofert®, NPK (08-09-09) (T7); Biofert ${ }^{\circledR}$, NPK (08-09-09) + banana (T8); Peters $®$, NPK (20-20-20) (T9); Peters®, NPK (20-20-20) + banana (T10); Plant Prod®, NPK (20-20-20) (T11); e Plant Prod®, NPK (20-20-20) + banana (T12). Os fertilizantes foram utilizados na concentração de $3 \mathrm{~mL} \mathrm{~L}^{-1}$ ou $3 \mathrm{~g} \mathrm{~L}^{-1}$, e a base dos meios de cultura foi composta por açúcar de uso doméstico $\left(30 \mathrm{~g} \mathrm{~L}^{-1}\right)$, carvão ativado $\left(1 \mathrm{~g} \mathrm{~L}^{-1}\right)$ e ágar $\left(9 \mathrm{~g} \mathrm{~L}^{-1}\right)$. Os meios foram avaliados com e sem a adição de polpa de banana-nanica $\left(100 \mathrm{~g} \mathrm{~L}^{-1}\right)$ no estádio de maturação quatro. $\mathrm{O} p H$ dos meios de cultura foi ajustado para $5,8 \pm 0,2$. Os frascos foram mantidos em sala de cultivo a $26^{\circ} \mathrm{C}$ e fotoperíodo de 16 horas.

Após 180 dias, as plântulas foram avaliadas analisando-se as seguintes variáveis: área foliar $\left(\mathrm{mm}^{2}\right)$, número de folhas e raízes, comprimento médio de raízes $(\mathrm{cm})$ e massas das matérias secas de folhas e raízes (g). Para a obtenção da área foliar utilizou-se o software ImageJ, e para a obtenção da massa da matéria seca, as folhas e raízes foram secas em estufa a $65^{\circ} \mathrm{C}$ até atingirem massa constante. O delineamento experimental foi inteiramente casualizado, composto de 12 tratamentos e seis repetições por tratamento, com sete plantas em cada repetição. Os resultados foram analisados por Análise de Variância (ANOVA), e as médias foram comparadas pelo Teste de Tukey a $5 \%$ de probabilidade. Os valores médios para as variáveis, número de folhas e raízes foram transformados para $\sqrt{\mathrm{x}+1}$.

\section{RESULTADOS E DISCUSSÃO}

A Tabela 1 apresenta as variáveis analisadas e os respectivos tratamentos. A área foliar das plântulas, no tratamento T2 se destacou em relação aos demais, não diferindo estatisticamente do tratamento T8.

Para número de folhas (Tabela 1), o tratamento T8 apresentou média superior à da maioria dos demais tratamentos, não diferindo apenas à do $\mathrm{T} 1 \mathrm{e}$ do $\mathrm{T} 4$. Possivelmente tais resultados tenham sido semelhantes devido aos fertilizantes (Brennfeed 114® e Biofert ${ }^{\circledR}$ ) e em razão de o meio MS ser composto pelos mesmos sais na sua grande maioria. 
Tabela 1. Médias de área foliar (AF), número de folhas (NF), massa de matéria seca de folhas (MSF), número de raízes (NR), comprimento médio de raízes (CMR) e massa de matéria seca de raízes (MSR) de plântulas de um híbrido de Phalaenopsis subcultivadas em diferentes meios de cultura após 180 dias de cultivo

\begin{tabular}{lclllll}
\hline Meios de cultura & $\mathbf{A F}\left(\mathbf{m m}^{2}\right)$ & $\mathbf{N F} * *$ & MSF $(\mathbf{g})$ & $\mathbf{N R} * *$ & CMR $(\mathbf{c m})$ & MSR $(\mathbf{g})$ \\
\hline T1 & $305,44 \mathrm{c}$ & $2,58 \mathrm{abc}$ & $0,02 \mathrm{bcd}$ & $5,11 \mathrm{abc}$ & $8,33 \mathrm{~d}$ & $0,03 \mathrm{f}$ \\
T2 & $667,76 \mathrm{a}$ & $2,45 \mathrm{bc}$ & $0,03 \mathrm{a}$ & $5,50 \mathrm{ab}$ & $18,86 \mathrm{ab}$ & $0,08 \mathrm{cde}$ \\
T3 & $242,69 \mathrm{c}$ & $1,65 \mathrm{~d}$ & $0,01 \mathrm{~cd}$ & $4,63 \mathrm{abcd}$ & $16,43 \mathrm{abc}$ & $0,07 \mathrm{de}$ \\
T4 & $266,26 \mathrm{c}$ & $2,67 \mathrm{ab}$ & $0,01 \mathrm{~cd}$ & $3,98 \mathrm{~cd}$ & $16,25 \mathrm{abc}$ & $0,11 \mathrm{bcd}$ \\
T5 & $300,33 \mathrm{c}$ & $2,28 \mathrm{bcd}$ & $0,01 \mathrm{~cd}$ & $4,77 \mathrm{abc}$ & $12,34 \mathrm{~cd}$ & $0,05 \mathrm{ef}$ \\
T6 & $224,31 \mathrm{c}$ & $2,40 \mathrm{bcd}$ & $0,01 \mathrm{~d}$ & $3,50 \mathrm{~d}$ & $13,89 \mathrm{bcd}$ & $0,08 \mathrm{cde}$ \\
T7 & $389,00 \mathrm{bc}$ & $2,31 \mathrm{bcd}$ & $0,01 \mathrm{~cd}$ & $5,48 \mathrm{ab}$ & $15,69 \mathrm{abc}$ & $0,06 \mathrm{ef}$ \\
T8 & $525,64 \mathrm{ab}$ & $3,26 \mathrm{a}$ & $0,03 \mathrm{a}$ & $5,76 \mathrm{a}$ & $17,19 \mathrm{abc}$ & $0,12 \mathrm{ab}$ \\
T9 & $384,29 \mathrm{bc}$ & $2,33 \mathrm{bcd}$ & $0,02 \mathrm{bcd}$ & $5,14 \mathrm{abc}$ & $12,51 \mathrm{~cd}$ & $0,05 \mathrm{ef}$ \\
T10 & $389,98 \mathrm{bc}$ & $2,38 \mathrm{bcd}$ & $0,02 \mathrm{ab}$ & $5,02 \mathrm{abc}$ & $19,89 \mathrm{a}$ & $0,15 \mathrm{a}$ \\
T11 & $326,55 \mathrm{c}$ & $1,88 \mathrm{~cd}$ & $0,02 \mathrm{bcd}$ & $5,24 \mathrm{ab}$ & $15,58 \mathrm{abc}$ & $0,07 \mathrm{de}$ \\
T12 & $281,14 \mathrm{c}$ & $2,05 \mathrm{bcd}$ & $0,02 \mathrm{bc}$ & $4,48 \mathrm{bcd}$ & $14,81 \mathrm{abc}$ & $0,11 \mathrm{abc}$ \\
\hline CV \% & 26,46 & 16,65 & 21,22 & 12,78 & 20,00 & 25,09 \\
\hline
\end{tabular}

T1 = MS modificado com metade dos macronutrientes; T2 = MS modificado com metade dos macronutrientes + banana; $\mathrm{T} 3=\mathrm{Brennfeed}$ $114 \circledast$ NPK (05-05-06); T4 = Brennfeed 114® NPK (05-05-06) + banana; T5 = Dyna-Gro® NPK (09-03-06); T6 = Dyna-Gro® NPK $(09-$ 03-06) + banana; T7 = Biofert@ NPK (08-09-09); T8 = Biofert ${ }^{\circledR}$ NPK $(08-09-09)+$ banana; T9 = Peters ${ }^{\circledR}$ NPK $(20-20-20) ;$ T10 $=$ Peters ${ }^{\circledR}$ NPK (20-20-20) + banana; T11 = Plant Prod ${ }^{\circledR}$ NPK (20-20-20); e T12 = Plant Prod ${ }^{\circ}$ NPK (20-20-20) + banana.

* Médias seguidas pela mesma letra não diferem entre si pelo teste de Tukey a 5\% de significância.

** Médias não transformadas.

Em relação à massa de matéria seca das folhas os tratamentos T2 e T8 destacaram-se com médias superiores, e T10 não diferiu destes tratamentos (Tabela 1).

Quanto ao número de raízes, T8 apresentou maior média, diferindo estatisticamente apenas dos tratamentos T4, T6 e T12 (Tabela 1). Araújo et al. (2006), estudando meio de cultura Knudson C para o desenvolvimento in vitro de plântulas de um híbrido de Cattleya, observaram maior número de raízes formadas quando os meios foram suplementados com 50 ou $100 \mathrm{~g} \mathrm{~L}^{-1}$ de polpa de bananananica e $100 \mathrm{~mL} \mathrm{~L}^{-1}$ de água de coco, sendo os menores valores obtidos em meios sem a polpa de banana. Os mesmos autores ainda concluíram que a adição de $100 \mathrm{~g} \mathrm{~L}^{-1} \mathrm{de}$ polpa de banana-nanica ao meio de cultura Knudson C promoveu o aumento da massa de matéria fresca de raízes, bem como o crescimento da parte aérea. Em relação à concentração de polpa de banana, Seeni \& Latha (2000) observaram maior número de raízes quando o meio nutritivo continha $35 \mathrm{~g} \mathrm{~L}^{-1}$ de polpa de banana.

O comprimento médio das raízes não diferiu estatisticamente para os tratamentos T2, T3, T4, T7, T8, T10 e T12. Porém, para massa de matéria seca das raízes foi constatado maior acúmulo em T10, seguido de T8 e T12 (Tabela 1).

Da Silva (2003) obteve melhores resultados na propagação in vitro de Cattleya tigrina A. Rich. utilizando um meio de cultura com fertilizante Dyna-Gro® (07-09-05), tomate e água de coco, quando comparado ao meio MS. Dronk (2004) também obteve melhores resultados na propagação de Cattleya amethystoglossa Linden \& Rchb. f. ex Warner utilizando meio de cultura com fertilizante DynaGro® (07-07-07), acrescido de banana e água de coco. Porém, a utilização fertilizante Dyna-Gro® (09-03-06) para o desenvolvimento in vitro de Phalaenopsis, não apresentou resultados satisfatórios, mesmo quando acrescido de polpa de banana.

Outros autores também verificaram efeito positivo no uso de fertilizantes comerciais em substituição aos sais do meio MS na formulação de meios de cultura para o desenvolvimento de várias espécies de orquídeas in vitro. Cunha et al. (2011), utilizando fertilizantes comerciais em meio de cultura para o cultivo de Laeliocattleya schilleriana, tiveram resultados superiores para todas as variáveis analisadas no meio composto pelo fertilizante Hyponex ${ }^{\circledR}(6,5-06-19)$.

Pedroso-de-Moraes et al. (2009), trabalhando com micropropagação de Cattleya tigrina em meios simplificados, observaram que a planta apresentou melhor desenvolvimento em meio composto com o fertilizante Kristalon Laranja ${ }^{\circledR}$ (06-12-36) quando comparado ao meio MS com metade da concentração de micronutrientes. Tal fertilizante apresenta os mesmos macro e micronutrientes encontrados no fertilizante Biofert ${ }^{\circledR}$.

\section{CONCLUSÃO}

O meio de cultura composto por Biofert $\circledast$, acrescido de polpa de banana, pode ser utilizado para o cultivo in vitro do híbrido de Phalaenopsis ( $P$. amabilis $\mathrm{x} P$. equestris) avaliado. 


\section{REFERÊNCIAS}

Araújo AG, Pasqual M, Villa F \& Costa FC (2006) Água de coco e polpa de banana no cultivo in vitro de plântulas de orquídea Revista Ceres, 53:608-613.

Arditti J \& Ernest R (1992) Micropropagation of orchids. $1^{\text {a }}$ ed. California, A Wiley - Interscience Publication. 680p.

Campos DM (2002) Orquídeas: Micropropagação e quimioterapia de meristemas. $1^{\text {a }}$ ed. Rio de Janeiro, Expressão e Cultura. 112p.

Cunha T, Cordeiro GM, Massaro R, Dezan LF \& Pedroso-deMoraes C (2011) Desenvolvimento in vitro de Laeliocattleya schilleriana Rolfe em meios de cultivo simplificados. Scientia Plena, 7:1-5

Da Silva ALL (2003) Avaliação de uma receita para o cultivo de orquídeas in vitro. Orquidário, 17:28-30.

Dronk AG (2004) Meios de cultura e condições de luminosidade para o cultivo in vitro de Cattleya amethystoglossa Linden \& Rchib. F. Dissertação de Mestrado. Universidade Federal do Paraná, Curitiba, 30p.

Faria RT, Santiago DC, Saridakis DP, Albino UB \& Araújo R (2002) Preservation of the Brazilian orchid Cattleya walkeriana Gardner using in vitro propagation. Crop Breeding and Applied Biotechnology, 2:489-492.

Faria RT, Assis AM, Unemoto LK \& Carvalho JFRP (2012) Produção de orquídeas em laboratório. $1^{\mathrm{a}}$ ed. Londrina, Editora Mecenas. $124 \mathrm{p}$.
Knudson L (1946) A new nutrient solution for the germination of orchid seed. American Orchid Society Bulletim, 14:214- 217.

Lee LL (2011) Biofábrica de Phalaenopsis. In: Lee TSG (Ed.) Biofábrica de plantas: Produção industrial de plantas in vitro. São Paulo, Antiqua. p.150-175.

Murashige T \& Skoog F (1962) A revised medium for rapid growth and biossays with tobacco tissue culture. Physiologia Plantarum, $15: 473-497$

Pedroso-de-Moraes C, Santos NS, Massaro R, Cordeiro GM \& Leal TS (2009) Desenvolvimento in vitro de Cattleya tigrina A. Richard (Orchidaceae) utilizando fertilizantes comerciais. Ensaios e Ciência: C. Biológicas, Agrárias e da Saúde, 13:57-65.

Seeni S \& Latha PG (2000) In vitro multiplication and ecorehabilitation of the endangered blue Vanda. Plant Cell Tissue and Organ Culture, 61:1-8.

Tsai CC, Huang SC, Huang PL \& Chou CH (2003) Phylogeny of the genus Phalaenopsis (Orchidaceae) with emphasis on the subgenus Phalaenopis based on the sequences of the internal transcribed spacers 1 and 2 of rDNA. Journal of Horticultural Science \& Biotechnology, 78:879-87.

Vacin E \& Went FW (1949) Some pH changes in nutrient solution. Bottanical Gazette, 110:605-613.

Vaz APA \& Kerbauy GB (2005) Orchidaceae. In: Terao D, Carva1ho ACPP \& Barroso TCSF (Eds.) Flores tropicais. Brasília, Embrapa Informação Tecnológica. p.25-41. 